\title{
Yanma yöntemi ile lantanit katkılı borat nano taneciklerin sentezi ve lüminesans özelliklerinin incelenmesi
}

\author{
Yusuf Ziya Halefoğlu', Serpil Işık² \\ ${ }^{1}$ Çukurova Üniversitesi, Güzel Sanatlar Fakültesi, Seramik Bölümü, Adana ,Türkiye; ORCID ID orcd.org/0000-0001-9871-0956 \\ ${ }^{2}$ Çukurova Üniversitesi, Fen Edebiyat Fakültesi, Kimya Bölümü, Adana, Türkiye
}

\section{MAKALE BILGISi}

Makale geşmişi:

İlk gönderi 01 Kasım 2017

Revize gönderi 23 Şubat 2018

Kabul 28 Mart 2018

Online 05 Temmuz 2018

\section{Araştırma Makalesi}

DOI: 10.30728/boron.348553

\section{Anahtar kelimeler:}

Lüminesans,

Borat,

Lantanit,

Yanma yöntemi

\begin{abstract}
ÖZET
$\mathrm{Bu}$ çalışmada, farklı lantanitler (Eu, Dy, $\mathrm{Nd}$ ) kullanılararak, lüminesans özellikli $\mathrm{NaCa}_{4-2 x}\left(\mathrm{BO}_{3}\right)_{3}: x A 1, \mathrm{~A} 2(\mathrm{~A} 1: \mathrm{A} 2$, Eu: Dy, Nd), (x=0,03, 0,05 ve 0,07) yapısında borat tanecikler sentezlenmiştir. Lantanit katkılı lüminesans maddelerin sentezlenmesi için, bugüne kadar bir çok çalışmada kullanılan katı hal yöntemi dışında, daha kolay, ucuz ve verimli olan yanma yöntemi kullanılmıştır. Sentezlenen maddelerde, fotolüminesans $(\mathrm{PL})$ spektroskopisi yöntemi kullanılarak katkılanan lantanitlerin, tuzak derinliklerinin ve (aktivatör ve ko-aktivatörlerin) derişimlerinin emisyon şiddeti üzerine etkisi incelenmiştir. Çoğunlukla Eu+'nin fosforesansının $4 \mathrm{f}-5 \mathrm{~d}$ geçişinden kaynaklandığı düşünülmektedir. Yapısal analizler $X$ ışını kırınımı (XRD), FTIR, Taramalı Elektron Mikroskobu (SEM) analizleri ile yapılmıştır. Farklı aktivatörlerin katkı oranlarına göre, kristal yapı ve bileşiklerin sönüm süreleri incelendiğinde, her bir aktivatörün, farklı katkı oranlarının emisyon şiddeti ve sönüm sürelerini etkilediği ortaya konmuştur. En şiddetli ışıma yapan Eu katkılı bileşiklerin, yapısal özellikleri ve emisyon şiddetleri ölçümleri yapılmıştır. Elde edilen PL spektrumlarına göre, koaktivatör konsantrasyonlarının arttırımasının emisyon şiddetinin artırıcı yönün tam tersine, ışıma şiddetinde azalmaya yol açtığı görülmüştür.
\end{abstract}

\section{Synthesis of lantanit doped borate nano particles with combustion method and Investigation of luminescence properties}

\section{ARTICLE INFO}

Article history:

Received 01 November 2017

Received in revised form 23 February 2018

Accepted 28 March 2018

Available online 05 July 2018

Research Article

DOI: $10.30728 /$ boron. 348553

Keywords:

Luminescence,

Borate,

Lanthanide,

Combustion method

\begin{abstract}
In this work, luminescent $\mathrm{NaCa}_{4-2 x}\left(\mathrm{BO}_{3}\right)_{3}$ : $\mathrm{xA} 1, \mathrm{~A} 2$ (A1:A2, Eu: Dy, $\left.\mathrm{Nd}\right), \quad(x=$ $0.03,0.05$ ve 0.07 ) structures borate particles were synthesized using different lanthanides (Eu, Dy, $\mathrm{Nd}$ ). An easy, inexpensive and efficient combustion method has been used to synthesize lanthanide-doped luminescent materials. The effects of photoluminescence (PL) spectroscopy on the radiant intensities of lanthanides, trap depths and activators and co-activators were investigated in the synthesized materials. It is generally believed that the phosphorus of $\mathrm{Eu}^{2+}$ is due to the $4 \mathrm{f}$ to $5 \mathrm{~d}$ transition. Structural analyzes were performed by X-ray diffraction (XRD), FTIR, Scanning Electron Microscopy (SEM) analyzes. When the damping times of the crystal structure and the compounds are examined according to the addition ratios of the different activators, it has been revealed that each activator influences the afterglow time and decay curve of the different additive ratios. Optimum ratios were determined for each compound. Structural properties and on light emisssion intensity of the Eu-doped compounds with the most intense luminescence were measured. According to the obtained PL spectra, it has been found that increasing the co-activator concentrations leads to a decrease in the intensity of radiation, contrary to the increasing direction of the emission intensity.
\end{abstract}

\section{Giriş (Introduction)}

Son yıllarda metal boratlar fiziksel ve optik doğası bakımından çok dikkat çeken bileşiklerdir [1-3]. Lüminesans malzemelerin önemli bir ailesi olan borat fosforların düşük sentez sıcaklığı, çeşitli yapıları ve iyi kimyasal ve fiziksel kararlıı̆ğından ötürü LED uygulaması büyük potansiyele sahiptir. Wu ve ark.
$\mathrm{NaCaBO}_{3}$ 'ün kristal yapısı verilerini bildirmiştir [4]. Son zamanlarda, çift emisyonlu $\mathrm{NaCaBO}_{3}: \mathrm{Ce}^{3+}, \mathrm{Mn}^{2+}$ fosforların lüminesans özellikleri J. Sun ve ark. tarafından tartışılmıştır [5]. Bir başka açıdan bu bileşiklerin optik, elektro-optik ve magnetik özellikleri bakımından çok ilgi çekmektedir [6-8]. 1980'lerin sonlarından itibaren, yanma sentezi reaksiyonu, homojen, kristalin ve ince tane boyutuna sahip fosforların üretimi için, daha 
uzun süreli katı hal yöntemi ve sol jel sürecine alternatif olarak keşfedilmiştir [9]. Bu yöntem, uygun oksitleyici (metal nitratlar, amonyum nitrat vb.) ve organik yakıtların (üre, karbohidraz veya gliserin) kullanılmasıyla oluşan hızlı, ekzotermik ve kendi kendini idame eden bir reaksiyon sağlar. Yanmanın gerçekleşmesinde, ürünlerin oluşumu sırasında yüksek miktarda ısı açığa çıkar. Alüminyum nitrat ve karbohidrazdan, alüminyum oksit eldesi negatif entropiye sahip oldukça yüksek ekzotermik reaksiyona bir örnektir. 1990'ların sonlarında, çeşitli araştırma grupları, oksit bazlı fosforların üretimi için yanma sentezi reaksiyonunu kullanmışlardır ve bu teknik birçok kişi için oldukça ilgi çekici hale gelmiştir. Oksit bazlı fosforlar için, yanma sentezi reaksiyonunun avantajı; geniş, zamanlı yüksek sıcaklık tavlaması ve mekanik ayrışma kademelerini gerektirmeyen kısa süreli bir süreçle iyi kristalize olmuş, ince boyutlu fosforların eldesine olanak sağlamasıdır [10].

Yeni borat malzemelerin, geniş bir kullanım alanı bulması araştırmacıları bu yöne sevk etmiştir. Borat bazlı malzemeler, UV yayıcı medikal lambalarda fosforesans kaynağı [Eu: $\mathrm{SrB}_{4} \mathrm{O}_{7}$ ] olarak, yüksek verimli floresan lambalarda yeşil ışık yayıcı bileşen [Ce,Tb:GdMgB $\left.{ }_{5} \mathrm{O}_{10}\right]$ olarak, televizyonda yüksek netlikte görüntü veren plazma ekran panellerinde kırmızı ışık yayıcı bileşen [Eu:(Y,Gd)BO $\mathrm{BO}_{3}$ ] olarak yaygın şekilde kullanılmaktadır. $\mathrm{\beta}_{-} \mathrm{BaB}_{2} \mathrm{O}_{4}(\mathrm{BBO}), \mathrm{LiB}_{3} \mathrm{O}_{5}$ (LBO) ve $\mathrm{CsLiB}_{3} \mathrm{O}_{5}$ (CLBO) gibi borat kristalleri sayesinde bugün artık, daha önce katı-hal sistemleriyle elde edilemeyen dalga boylarında ve gücünde lazer ışığı üretilebilmektedir. Bu performans karakteristiklerinden dolayı söz konusu kristaller malzeme işlenmesinde, tıpta, araştırma/geliştirme alanlarında yaygın olarak kullanılmaya başlanmıştır. Yapılan çalışmalarda, bazı borat fosforların, $\mathrm{LiSr}_{4}\left(\mathrm{BO}_{3}\right)_{3}: \mathrm{Ce}^{3+}$ (mavi) [11], $\mathrm{Ca}_{2} \mathrm{BO}_{3} \mathrm{Cl}: \mathrm{Eu}^{2+}$ (sarı) [12], $\mathrm{Li}_{6} \mathrm{Y}\left(\mathrm{BO}_{3}\right)_{3}: \mathrm{Eu}^{3+}$ (kırmızı) [13] renk verdikleri bildirilmiştir.

Temel bilgiye katkı düzeyinde ise boratlar üzerindeki araştırmalar, başka herhangi bir tipte malzeme ile ulaşılamayan, bazı fiziksel özelliklere sahip yeni bileşiklerin keşfi ve teşhisi için özel fırsatlar ortaya koymaktadır. Makro ölçekli bu özellikler, mikro ölçekte bakıldığında, çok küçük olan bor atomunun, bir oksit matriksi içine dağılması sonucu oluşan benzersiz kristal yapılardan ve elektronik özelliklerden ileri gelmektedir.

Az oranlarda $\mathrm{Eu}^{2+}$ eklenmiş oksitlerin çoğunda, uyarılma mor ötesi bölgesinde meydana gelir ve uyarılmanın hemen sonrasında mor ötesi, mor veya mavi dalga boylarında ışıma emisyonu gerçekleşir. Oysaki $\mathrm{Eu}^{2+}$ katkılanmış $\mathrm{Ba}_{2} \mathrm{LiB}_{5} \mathrm{O}_{10}$ ve $\mathrm{Ba}_{2} \mathrm{Mg}\left(\mathrm{BO}_{3}\right)_{2}$ bileşiklerinde, spektrumun kırmızı bölgesine kadar kayan uzun dalga boylu emisyon gözlenmiştir. Geçmişte, emisyonun dalga boyu, büyük ölçüde katkılanan iyonun (burada $\mathrm{Eu}^{2+}$ ) çevresi temel alınarak açıklanmıştır. Yeni geliştirilen bir modelde ise emisyon mekanizması yeniden yorumlanmıştır [14]. Yeni modelde, mekanizma oksijenin koordinasyon sayılarına ve geometrilerine bağlanmış ve böylece boratlarda gözlenen geniş uyarılma aralığı ile $\mathrm{Eu}^{2+}$ 'de görülen yaygın emisyon enerjileri açıklanabilmiştir. Bu modele göre, uzun dalga boylu (yeşil ve kırmızı) Eu ${ }^{2+}$ emisyonu, üç veya daha fazla sayıda ağır atom (Ba, Sr gibi) tarafından sarılmış $\mathrm{O}$ atomları içeren konukçularda gözlenirken, kısa dalga boylu emisyon, sadece bir veya iki Ba/Sr atomuyla koordine olmuş $\mathrm{O}$ atomları içeren bileşiklerde gözlenir. O koordinasyon çevrelerinin ideal geometrilerden sapması da daha uzun boylu emisyona neden olur.

Literatür çalışmaları özetle incelendiğinde fosforesans özellik gösterebilen madde grupları olarak belirlenen sülfür, oksit, silikat, alümina ve fosfatların yanı sıra, borat kristal yapıya sahip maddelerinde ışıma özelliği gösterebileceği tespit edilmiştir $[15,16]$.

Bu çalışmada, yanma yönteminin avantajları kullanılarak, farklı lantanit elementlerin katkılanması ile, $\mathrm{NaCa}_{4-2 x}\left(\mathrm{BO}_{3}\right)_{3}: x A 1, x A 2$ yapısında bileşiğin lüminesans özellikleri, kristal yapı ve lantanit element katkı miktarlarının emisyon şiddeti üzerine etkileri incelenmiştir. Yanma yöntemi, ucuz, ekipman gerektirmeyen, öğütme avantajı sağlayan ve çok kısa sürede reaksiyonun gerçekleşmesinden dolayı ekonomik bir yöntem olduğu için tercih edilmiştir.

\section{Malzemeler ve yöntemler (Materials and methods)}

Çalışmada, XRD için RigakuRadB-Dmax II bilgisayar kontrollü X-Işınları difraktometresi, SEM / EDX'ler için Brucker marka, FT-IR için Mattson 1000 cihazı Perkin Elmer Spektrum RXIFT-IR first marka satellite, Shimadzu RF-5301 PC spektroflorometre 8 A, 1200 ${ }^{\circ} \mathrm{C}$ 'lik Protherm programlanabilir fırın, CAMAG marka kabinli UV lamba (254 nm/365 nm), agat havan, porselen küvet kullanılmıştır. Kimyasal madde olarak; üre $\mathrm{CO}\left(\mathrm{NH}_{2}\right)$, borik asit $\left(\mathrm{H}_{3} \mathrm{BO}_{3}\right)$, kalsiyum nitrat tetrahidrat $\left(\mathrm{Ca}\left(\mathrm{NO}_{3}\right)_{2} \cdot 4 \mathrm{H}_{2} \mathrm{O}\right)$, sodyum nitrat $\left(\mathrm{NaNO}_{3}\right)$, yüropyum (III) nitrat hekzahidrat $\left(\mathrm{Eu}\left(\mathrm{NO}_{3}\right)_{3} \cdot 6 \mathrm{H}_{2} \mathrm{O}\right)$, neodmiyum (III) nitrat hekzahidrat $\left(\mathrm{Nd}\left(\mathrm{NO}_{3}\right)_{3} \cdot 6 \mathrm{H}_{2} \mathrm{O}\right)$, disporsiyum (III) nitrat pentahidrat $\left(\mathrm{Dy}\left(\mathrm{NO}_{3}\right)_{3} \cdot 5 \mathrm{H}_{2} \mathrm{O}\right.$ kullanılmıştır.

Kullanılan kimyasal malzemeler Merck, Alfa Aesar firmalarından \%99,5-100 saflıkta temin edilmiştir.

$\mathrm{NaCa}_{4-2 x}\left(\mathrm{BO}_{3}\right)_{3}: x \mathrm{~A} 1, x \mathrm{~A} 2$ sentezi; ana kristal yapı $\mathrm{NaCa}_{4}\left(\mathrm{BO}_{3}\right)_{3}$ oluşturulacak şekilde $0,5 \mathrm{~g} \mathrm{NaNO}_{3}, 6,54$ $\mathrm{g} \mathrm{Ca}\left(\mathrm{NO}_{3}\right)_{2} .4 \mathrm{H}_{2} \mathrm{O}, 1,625 \mathrm{~g} \mathrm{H}_{3} \mathrm{BO}_{3}$ (\%30 aşırısı) ve 3,33 g CO$\left(\mathrm{NH}_{2}\right)_{2}$ reaksiyona giren madde miktarları stokiyometrik olarak hesaplanmış ve tartılarak agat havanda öğütülmüştür. Öncelikle karışım çözelti oluşturana kadar manyetik karıştırıcıda karışıtırılarak ısıtılmış ve daha sonra, ana kristal yapı $\mathrm{NaCa}_{4}\left(\mathrm{BO}_{3}\right)_{3}$ içerisine katkılanacak olan farklı \% değerleri $\left(x_{1}, x_{2}, x_{3} \ldots\right)$ ve farklı oranlarında (aktivatör/ko-aktivatörler (1/2, 1/3 ve $1 / 4,2 / 1)), \mathrm{A} 1\left(\mathrm{NO}_{3}\right)_{3}$ ve $\mathrm{A} 2\left(\mathrm{NO}_{3}\right)_{3}$ tartılıp, karışıma eklenerek katkılama yapılmış (1), homojen şeffaf jel oluşana kadar karıştırmaya devam edilmiştir.

$$
\mathrm{NaNO}_{3}+4 \mathrm{Ca}\left(\mathrm{NO}_{3}\right)_{2}+8 \mathrm{CO}\left(\mathrm{NH}_{2}\right)_{2}+3 \mathrm{H}_{3} \mathrm{BO}_{3} \rightarrow \mathrm{NaCa}_{4}\left(\mathrm{BO}_{3}\right)_{3}+12 \mathrm{~N}_{2}+8 \mathrm{CO}_{2}+\mathrm{NH}_{3}+19 \mathrm{H}_{2} \mathrm{O}
$$


Hazırlanan örnek, seramik kroze içerisinde normal atmosferdeki kül fırınına yerleştirilmiştir. Fırın ısındıkça karışım kaynamaya başlamış ve reaksiyon ortamından $\mathrm{N}_{2}, \mathrm{CO}_{2}$ gibi, gazların uzaklaşması ile karışım dehidratasyona uğramıştır. Köpüren karışımdan yanıcı gazların tutuşması sonucu kırılgan kabarcıklı beyaz köpük görünümlü madde elde edilmiştir. Reaksiyon, $550{ }^{\circ} \mathrm{C}$ de 5 dakikada gerçekleşmiş ve bunun üzerine 1 saat bekletilmiştir. Daha sonra elde edilen $\mathrm{NaCa}_{4-2 x}\left(\mathrm{BO}_{3}\right)_{3}: x A 1, x A 2$ ürünü oda sıcaklığına kadar soğutulup tekrar öğütülerek $800{ }^{\circ} \mathrm{C}$ de 2 saat süre ile normal atmosferde kalsine edilmiştir.

Malzemelerin iç yapısının morfolojik özelliklerinin tanımlanması aşamasında ve kristal yapının incelenmesinde X-ışınları analizleri oldukça önemli bulgular sağlar. Ölçüm sonuçlarına göre yapısal analizler, Rietvelt yapısal analiz metodu temelli çalışan Match 2 programı aracılığıyla, Ortorombik yapı, Ama 2 uzay grubu referans alınarak ve PseudoVoigt fonksiyonu ile yapılmıştır [17].

Elde edilen maddelerin kristal boyutları, $D$, ise $X$ ışını kırınım ölçümlerinden elde edilen verilerden ve Debye- Scherrer formülü (2) yardımıyla hesaplanmıştır,

$D=\frac{k \lambda}{\beta \cos \theta}$

Burada k, kristal faktörüdür (0,94 olarak kabul edilmiştir), $\lambda, X$-ışını dalga boyudur (Cu- $\left.\mathrm{K}_{\alpha}=1,5406 \AA\right), \beta, \theta$ pik açısında gözlenen maksimum yüksekliğin yarı genişliğidir (radyan cinsinden).

\section{Sonuçlar ve tartışma (Results and discussion)}

Yanma yöntemi ile $550{ }^{\circ} \mathrm{C}$ sentezlenen katkısız $\mathrm{NaCa}_{4}\left(\mathrm{BO}_{3}\right)_{3}$, bileşiğinin $10^{\circ} \leq 2 \theta \leq 70^{\circ}$ aralığında alınan XRD kırınım deseni Şekil 1'de, örgü parametreleri ise Çizelge 1'de verilmiştir.

Şekil 1'de verilen $\mathrm{NaCa}_{4}\left(\mathrm{BO}_{3}\right)_{3}$ bileşiği için, ortorombik yapıya ait karakteristik keskin piklerin $2 \theta=30^{\circ}$ ve $2 \theta=32^{\circ}$ civarında oluştuğu dolayısıyla kristalleşmenin gerçekleştiği görülmektedir. Bileşiğin kristal yapısının belirlenmesi örgü parametreleri ve birim hücre hacminin hesaplanabilmesi için Panalytical X'Pert High

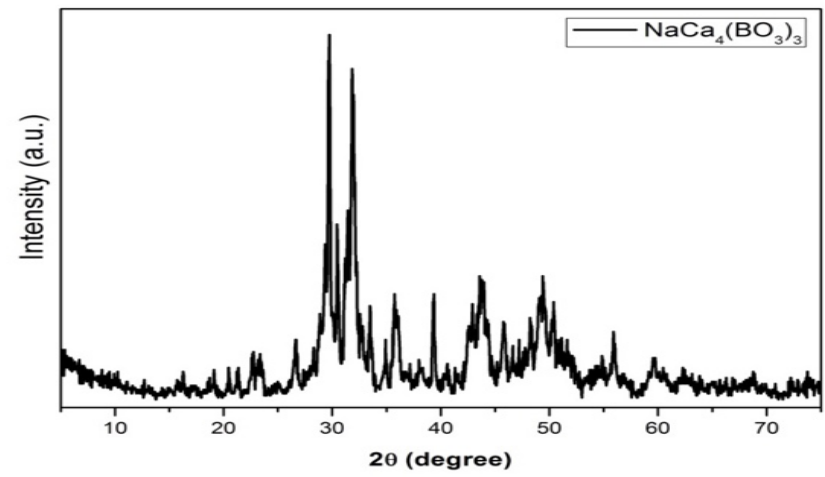

Şekil 1. Yanma yöntemi ile sentezlenen $\mathrm{NaCa}_{4}\left(\mathrm{BO}_{3}\right)_{3}$ yapısı XRD paterni (XRD pattern obtained for $\mathrm{NaCa}_{4}\left(\mathrm{BO}_{3}\right)_{3}$ prepared by combustion method).

Çizelge 1. $\mathrm{NaCa}_{4}\left(\mathrm{BO}_{3}\right)_{3}$ yapısına ait örgü parametreleri (The lattice parameters of $\left.\mathrm{NaCa}_{4}\left(\mathrm{BO}_{3}\right)_{3}\right)$.

\begin{tabular}{llll}
\hline Numune & $\mathbf{a}(\mathbf{A})$ & $\mathbf{b}(\hat{\AA})$ & $\mathbf{c}(\mathbf{A})$ \\
\hline $\mathrm{NaCa}_{4}\left(\mathrm{BO}_{3}\right)_{3}$ & 10,976 & 8,69 & 6,48 \\
\hline
\end{tabular}

Score Plus ve Match 2 programları kullanılmıştır. Yapılan analiz sonucunda $\mathrm{NaCa}_{4}\left(\mathrm{BO}_{3}\right)_{3}$ bileşiğinin Ama 2 uzay grubunda ve ortorombik yapıda olduğu bulunmuştur. Çizelge 1'de verilen hesaplanmış örgü parametrelerinin literatürdeki ortorombik yapı için verilen değerler [17] ile uyumlu bulunmuştur. DebyeScherrer formülü yardımıyla elde edilen kristal boyutu D, 36,75 nm olarak hesaplanmıştır.

Lantanit Katkılı $\mathrm{NaCa}_{(4-2 \mathrm{x})}\left(\mathrm{BO}_{3}\right)_{3} ; \mathrm{xA} 1, \mathrm{xA} 2$ (A1:Eu, A2:Dy, Nd), (x=0,03, 0,05 ve 0,07) Maddeleri için XRD Sonuçları; $\mathrm{NaCa}_{4}\left(\mathrm{BO}_{3}\right)_{3}: x A 1 ; x A 2$ bileşiğinin $\mathrm{Na}$ elementi bölgesinde belirli konsantrasyonlarda $(x=0,03$, 0,05 ve 0,07 için) lantanit elementleri $(\mathrm{A} 1 ; \mathrm{A} 2)$ ile $\mathrm{Na}$ elementi yer değiştirecek şekilde yapılan katkılama ile elde edilen bileşiklerin kristalleşmelerinin oluşup oluşmadığını belirlemek için XRD ölçümleri yapılmıştır. $2 \theta=10^{\circ}-70^{\circ}$ aralığında sabit tarama hızında oda sıcakIığında elde edilen XRD kırınım desenleri Şekil 2'de verilmiştir. Ayrıca XRD verilerinden hesaplanan örgü parametreleri Çizelge 2'de belirtilmiştir. Debye-Scherrer formülü yardımıyla elde edilen kristal boyutları ise Çizelge 3’te verilmiştir.
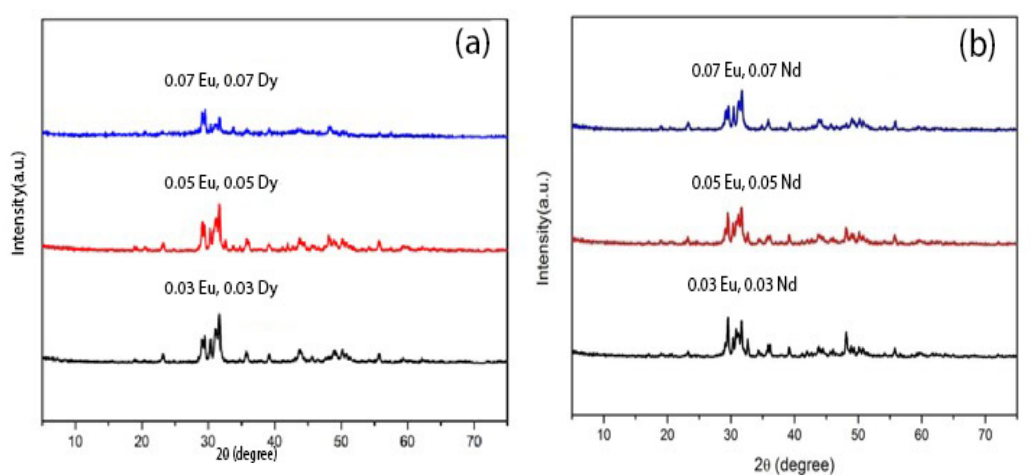

Şekil 2. (a) $\mathrm{NaCa}_{4-2 x}\left(\mathrm{BO}_{3}\right)_{3} ; \mathrm{xEu}, \mathrm{x}(\mathrm{Dy})\left(\mathrm{x}=0,03,0,05\right.$ ve 0,07 için) (b) $\mathrm{NaCa}_{4-2 x}\left(\mathrm{BO}_{3}\right)_{3} ; \mathrm{xEu}, \mathrm{x}(\mathrm{Nd})(\mathrm{x}=0,03,0,05$ ve 0,07 için) yapısı için XRD desenleri (XRD patterns obtained for (a) $\mathrm{NaCa}_{4-2 x}\left(\mathrm{BO}_{3}\right)_{3} ; \mathrm{xEu}, \mathrm{x}(\mathrm{Dy})\left(\mathrm{x}=0.03,0.05\right.$ ve 0.07) (b) $\mathrm{NaCa}_{4-2 x}\left(\mathrm{BO}_{3}\right)_{3} ; \mathrm{xEu}, \mathrm{x}(\mathrm{Nd})$ $(x=0.03,0.05$ ve 0.07$))$. 
Çizelge 2. $\mathrm{NaCa}_{4-2 x}\left(\mathrm{BO}_{3}\right)_{3} ; \mathrm{xEu}, \mathrm{x}(\mathrm{Dy}-\mathrm{Nd})(\mathrm{x}=0,03,0,05$ ve 0,07$)$ için örgü parametreleri (The lattice parameters of $\mathrm{NaCa}_{4-}$ ${ }_{2 x}\left(\mathrm{BO}_{3}\right)_{3} ; \mathrm{xEu}, \mathrm{x}(\mathrm{Dy}-\mathrm{Nd})(\mathrm{x}=0.03,0.05$ and 0.07$)$.

\begin{tabular}{|c|c|c|c|c|c|c|c|c|}
\hline$x$ & $a(\AA)$ & $a(\AA)$ & $b(\AA)$ & $b(\AA)$ & $c(\AA)$ & $c(\AA)$ & $V\left(A^{3}\right)$ & $V\left(\AA^{3}\right)$ \\
\hline 0,03 & 10,9 & 1075 & 8,69 & 8,60 & 6,48 & 6,56 & 617,8 & 606,7 \\
\hline 0,05 & 10,69 & 11,13 & 8,58 & 8,58 & 6,18 & 6,42 & 566,8 & 612,2 \\
\hline 0,07 & 11,05 & 11,37 & 9,05 & 8,56 & 7,02 & 6,45 & 701,9 & 627,3 \\
\hline
\end{tabular}

Çizelge 3. $\mathrm{NaCa}_{4}\left(\mathrm{BO}_{3}\right)_{3} ; \mathrm{xA} 1, \mathrm{xA} 2(\mathrm{x}=0,03,0,05$ ve 0,07$)$ için kristal boyutlar $D(\mathrm{~nm})$ (The crystal dimensions $D(\mathrm{~nm})$ for $\mathrm{NaCa}_{4}\left(\mathrm{BO}_{3}\right)_{3} ; \mathrm{xA} 1, \mathrm{xA} 2(\mathrm{x}=0.03,0.05$ ve 0.07$\left.)\right)$.

\begin{tabular}{ccc}
\hline \multirow{2}{*}{} & \multicolumn{2}{c}{ A1;A2 } \\
\cline { 2 - 3 } & Eu;Dy & Eu:Nd \\
\hline 0,03 & $25,53 \mathrm{~nm}$ & $64,31 \mathrm{~nm}$ \\
0,05 & $30,46 \mathrm{~nm}$ & $56.79 \mathrm{~nm}$ \\
0,07 & $34,06 \mathrm{~nm}$ & $33,46 \mathrm{~nm}$ \\
\hline
\end{tabular}

Her bir XRD analizinde ana yapının yanında safsızlık piklerinin de bulunduğu görülmüştür. Bu safsızlık yapılarının tespit edilmesinde X' Pert High Score Plus programı kullanılmıştır. Bu program ile yapılan analiz sonucunda safsızlık piklerinin Şekil 3'de görüldüğü gibi ICDD- (01-070- 0868) $\mathrm{Ca}_{3}\left(\mathrm{BO}_{3}\right)_{2}$ yapısına ait olduğu öne sürülebilir.

Yanma reaksiyonu ile düşük sıcaklıklarda başlangıçta daha kararsız diğer yan ürünlerin oluşmasına rağmen ana yapıya ait keskin referans piklerinin gözlenmesi, istenilen $\mathrm{NaCa}_{4}\left(\mathrm{BO}_{3}\right)_{3}$ ana yapısının oluştuğunun kanitıdır [17].

Ana kristale yapılan lantanit katkılama miktarındaki artışa bağlı olarak çok az da olsa kaymalar ve şiddet değerlerinde değişimler gözlenmiştir. Piklerin şiddetindeki artma ve azalmaların yapılan katkı miktarlarına bağlı olarak daha önce oluşan bazı fazların bozularak yeni fazlar ortaya çıkışından kaynaklandığı düşünülmektedir.

Şekil 2'de verilen piklerden görüldüğü üzere, bu bileşiklerde karakteristik piklerin, dar tabanlı keskin olma
Özelliğini genel anlamda korudukları söylenebilir. Bu durum da bileşiklerin yapısal özelliklerinin katkılama ile çok değişmediği şeklinde yorumlanabilir.

Tüm bileşikler için örgü parametreleri birlikte değerlendirildiğinde farklı konsantrasyonlarda yapılan katkılamalara bağlı olarak parametre ve birim hacimlerdeki değişimlerin yarıçap farkından kaynaklandığını söyleyebiliriz. Yarıçap değerleri farklılığından da anlaşılacağı gibi $\mathrm{Ca}^{2+}$ iyonunun yarıçapı ile katkılama yapılan lantanit iyonlarının yarıçapı arasındaki büyüklük farkından dolayı, Ca iyonundan eksiltilerek, eksilen miktar kadar lantanit doplaması yapıldığından rahatlıkla iyonlar arasında yer değişimin gerçekleştiği söylenebilir.

Şekil 4'te FTIR sonucu verilen $\mathrm{NaCa}_{4}\left(\mathrm{BO}_{3}\right)_{3}$;Eu,Dy yapısında yer alan spesifik $\mathrm{B}-\mathrm{O}$ bağlarına ait pik değerleri Çizelge 4'te verilmiştir.

$\mathrm{NaCa}_{4}\left(\mathrm{BO}_{3}\right)_{3}$ yapısındaki B-O koordinasyon çevresinin daha da iyi doğrulanabilmesi açısından oda sıcakIığında FT-IR spektrumları alınmıştır. Şekil 5'te FTIR sonucu verilen $\mathrm{NaCa}_{4}\left(\mathrm{BO}_{3}\right)_{3} ; \mathrm{Eu}, \mathrm{Nd}$ yapısında yer alan spesifik $\mathrm{B}-\mathrm{O}$ bağlarına ait pik değerleri Çizelge 5 'te verilmiştir.

B-O titreşim frekansları bor koordinasyonuna bağlıdır. Koordine $\mathrm{BO}_{n}$ gruplarının gerilme frekansları koordinasyon sayısı, n arttıkça azalır [18]. Şekil 5'te verilen spektrum ve Çizelge 5'te FTIR veri sonuçlarına bakıldığında, $\mathrm{BO}_{3}$ grubunda yer alan asimetrik $\mathrm{B}-\mathrm{O}$ bağ gerilim bantlarının 1150-1500 $\mathrm{cm}^{-1}$ aralığında yer aldığı gözlenmiştir. $\mathrm{BO}_{3}$ gruplarının kümeleşmesi ile ilkinin (oksijene bağlı tek B atomu olan) kısa B-O bağının olduğu diğerinin ise daha uzun olan -O-B bağının olduğu iki tür B-O bağı oluştuğu görülmüştür. B-O
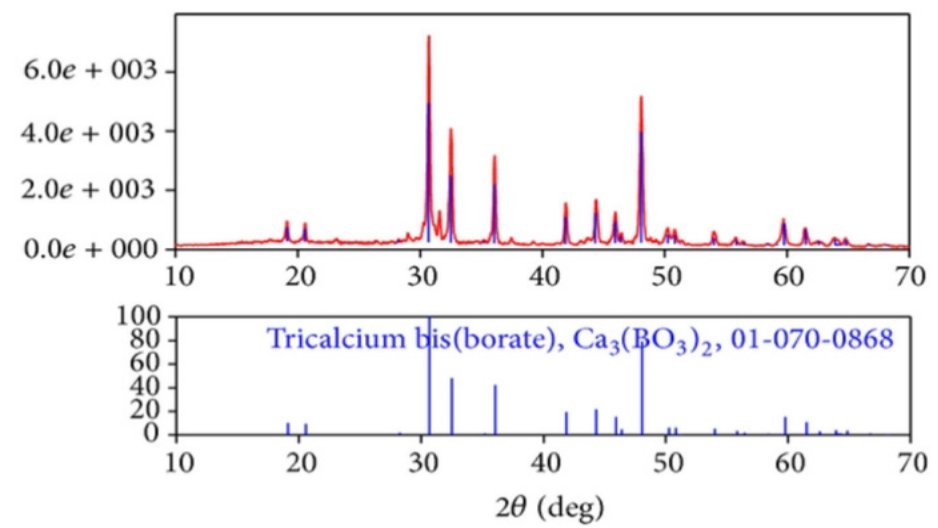

Şekil 3. $\mathrm{Ca}_{3}\left(\mathrm{BO}_{3}\right)_{2}$ yapısına ait ICDD-(01-070- 0868) kartı (ICDD-(01-070- 0868) card of $\mathrm{Ca}_{3}\left(\mathrm{BO}_{3}\right)_{2}$ structure). 


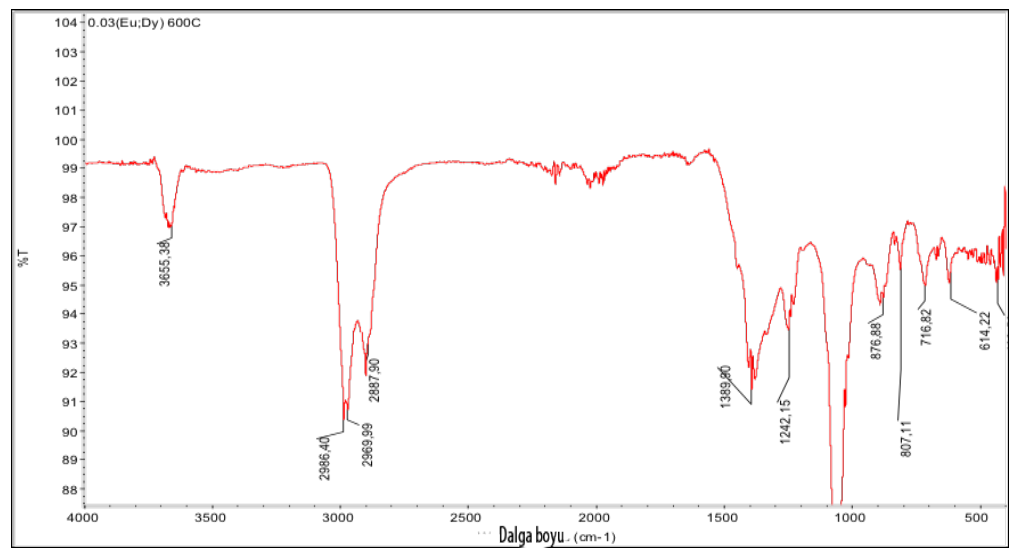

Şekil 4. $\mathrm{NaCa}_{4}\left(\mathrm{BO}_{3}\right)_{3}: \mathrm{Eu}$, Dy yapısı için FT-IR pikleri (FT-IR spectra of $\left.\mathrm{NaCa}_{4}\left(\mathrm{BO}_{3}\right)_{3}: \mathrm{Eu}, \mathrm{Dy}\right)$.

Çizelge 4. $\mathrm{NaCa}_{4}\left(\mathrm{BO}_{3}\right)_{3}: \mathrm{Eu}$, Dy yapısına ait FTIR verileri (FTIR data for the structure $\mathrm{NaCa}_{4}\left(\mathrm{BO}_{3}\right)_{3}: \mathrm{Eu}$, Dy).

\begin{tabular}{cc}
\hline Titreşimler & Dalga Sayısı $\left(\mathbf{c m}^{-1}\right)$ \\
\hline$v_{3}\left(\mathrm{BO}_{3}\right)_{3}$ & 1389,1241 \\
$v_{1}\left(\mathrm{BO}_{3}\right)_{3}$ & 1100 \\
$v_{2}\left(\mathrm{BO}_{3}\right)_{3}$ & $876,807,716$ \\
$v_{4}\left(\mathrm{BO}_{3}\right)_{3}$ & 614 \\
\hline
\end{tabular}

Çizelge 5. $\mathrm{NaCa}_{4}\left(\mathrm{BO}_{3}\right)_{3} ; \mathrm{Eu}, \mathrm{Nd}$ yapısına ait $\mathrm{FTIR}$ verileri (FTIR data for the structure $\mathrm{NaCa}_{4}\left(\mathrm{BO}_{3}\right)_{3}: \mathrm{Eu}, \mathrm{Nd}$ ).

\begin{tabular}{cc}
\hline Titreşimler & Dalga Sayısı $\left(\mathbf{c m}^{-1}\right)$ \\
\hline$v_{3}\left(\mathrm{BO}_{3}\right)_{3}$ & 1392,1219 \\
$v_{1}\left(\mathrm{BO}_{3}\right)_{3}$ & 1059,1014 \\
$v_{2}\left(\mathrm{BO}_{3}\right)_{3}$ & $890,833,735$ \\
$v_{4}\left(\mathrm{BO}_{3}\right)_{3}$ & $667,660,653,616$ \\
\hline
\end{tabular}

gerilme frekansları $1200-1450 \mathrm{~cm}^{-1}$ civarında ikili bant ya da bant grupları halinde oluşmaktadır $[17,18,19]$. Örneklerin FT-IR sonuçlarından görüldüğü gibi $\left[\mathrm{BO}_{3}\right]^{3-}$ gruplarının varlığını doğrulayan düzlem dışı B-O bükülmeleri max. 700-800 cm-1 aralığında gözlenirken, üçgensel $\left[\mathrm{BO}_{3}\right]^{3-}$ gruplarının $\mathrm{B}-\mathrm{O}$ gerilimini gösteren güçlü bantlar ise $1100 \mathrm{~cm}^{-1}$ üzerinde oluşmuştur $[17,18,19] .1500-2000 \mathrm{~cm}^{-1}$ aralığındaki piklerin varlığı yapıdaki organik madde ve nitratların, $3300-3500 \mathrm{~cm}^{-1}$ aralığındaki pikler ise yapıdaki O-H gerilmelerinin göstergesidir [20]. Ayrıca; farklı B-O bağ uzunluklarından kaynaklanan $1100 \mathrm{~cm}^{-1}$ üzerinde birbirine çok yakın piklerin de varlığı gözlenmektedir.

Şekil 6'da termal analiz eğrisi verilen maddenin $20^{\circ} \mathrm{C} /$ dk. hız ile ortalama $20{ }^{\circ} \mathrm{C}$ 'den $1100{ }^{\circ} \mathrm{C}$ ' ye artan sıcaklığa maruz kalarak analizi yapılmıştır. Borat kristal yapısındaki lüminesans maddelerin elde edilen termal grafiklerinden belirli noktalarda ayrışma, kopmaların olduğunu gözlenmiştir.

$200{ }^{\circ} \mathrm{C}$ 'den daha düşük sıcaklıktaki ilk kütle kaybı, yüzeye adsorbe olan su ya da kalan suyu moleküllerinin dehidratasyonundan kaynaklanabilir. Kütle kaybındaki ikinci ve üçüncü adımları ortalama $150^{\circ} \mathrm{C}-700^{\circ} \mathrm{C}$ araIığında metal nitratların ve organik ligantların, ürenin ayrışması aşamasıdır. Son kütle kaybının gerçekleştiği aşama ortalama ise $750^{\circ} \mathrm{C}$ sonrası ürünün kararlı hale geldiği kristalizasyon prosesinin gerçekleştiği kısımdır $[21,22]$. Sentezlenen $\mathrm{NaCa}_{4}\left(\mathrm{BO}_{3}\right)_{3}$ ana kristal yapının termal analiz sonucundan yapıda çok küçük safsızlıklardan dolayı parçalanmalar görünmesine rağmen asıl yapı korunduğunu söyleyebiliriz.

Şekil 7'de görüldüğü gibi fotolüminesans uyarılma ve emisyon spektrumları oda sıcaklığında kayıt edilmiştir. Tipik uyarılma spekturumu, $\lambda_{\mathrm{em}} 480 \mathrm{~nm}$ de

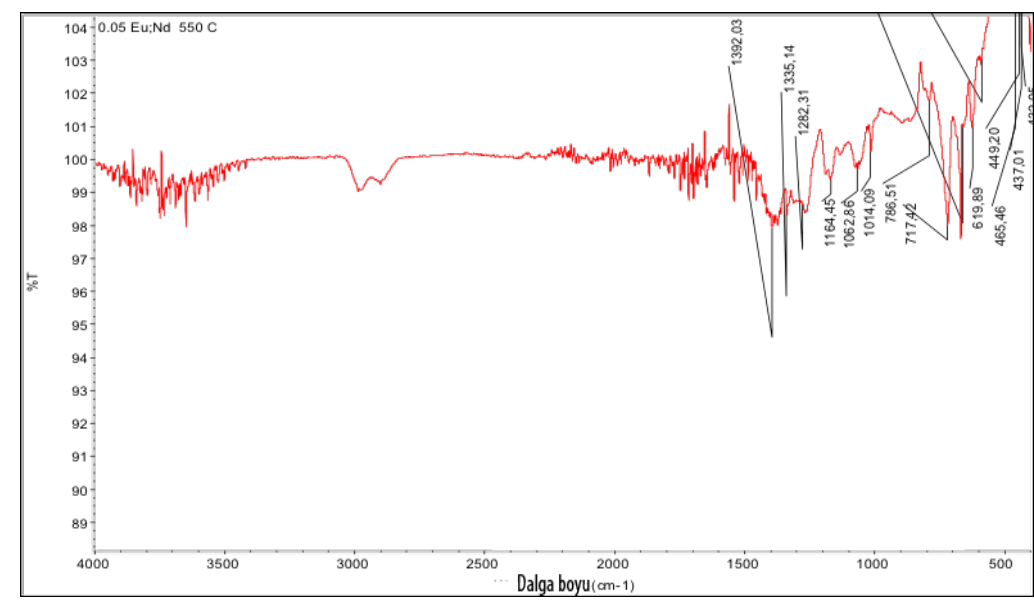

Şekil 5. $\mathrm{NaCa}_{4}\left(\mathrm{BO}_{3}\right)_{3}$; Eu, Nd yapısı için FT-IR pikleri (FTIR spectra of $\mathrm{NaCa}_{4}\left(\mathrm{BO}_{3}\right)_{3}$ : $\left.\mathrm{Eu}, \mathrm{Nd}\right)$. 


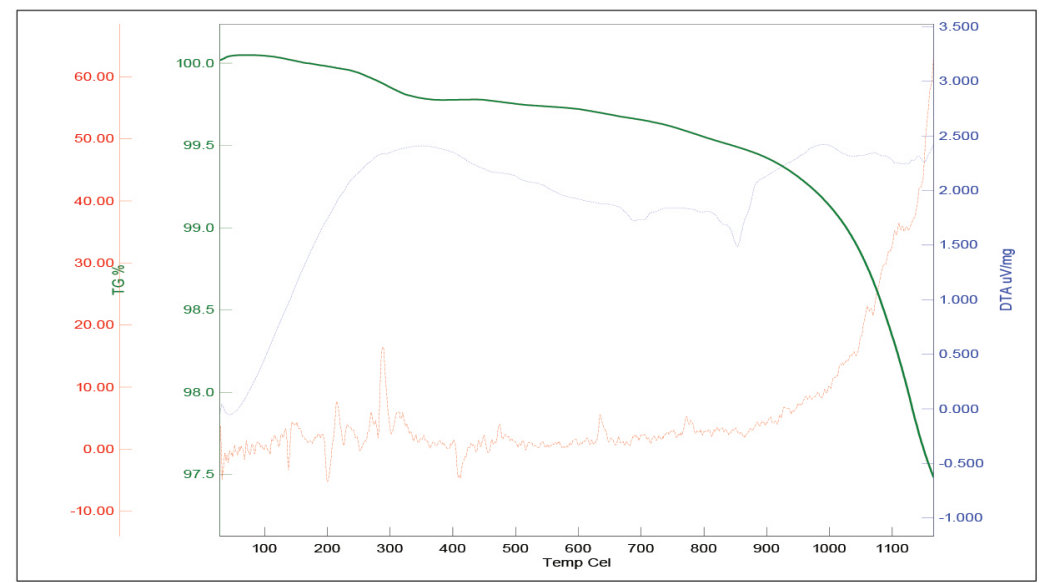

Şekil 6. $\mathrm{NaCa}_{4}\left(\mathrm{BO}_{3}\right)_{3}$ maddesine ait $20^{\circ} \mathrm{C} / \mathrm{dk}$. Isıtma hızında alınan TG/ DTA eğrisi (TG/DTA curve of $\mathrm{NaCa}_{4}\left(\mathrm{BO}_{3}\right)_{3}$ material obtained at $20^{\circ} \mathrm{C} / \mathrm{min}$ heating rate).

300-400 nm aralığında tespit edilmiştir. Bu durumun $\mathrm{Eu}^{2+}$ fosforesansının genellikle 4f-5d geçişinden kay-

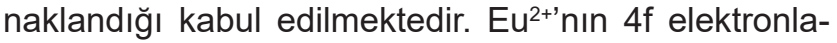
rı, en dış kabuğun kalkan görevi görmesi dolayısıyla, yapıdaki değişikliklere karşı güçlü olmasına rağmen, $5 d$ elektronları bu değişimlerle kolayca ayrılabilir $[23,24]$. Fakat fosforesans açısından Dy'nin $\mathrm{NaCa}_{4}$ ${ }_{2 x}\left(\mathrm{BO}_{3}\right)_{3}$ :Eu'da boşluk tutucu şeklinde davrandığı ve oda sıcaklığında ısıl boşalma oranıyla alakalı olarak uygun derinlikte ve yüksek yoğunlukta tutuculuk sağladığı düşünülmektedir [25]. Lüminesans şiddeti her zaman aktivatör lantanit elementin konsantrasyonuna bağlı olarak değişmektedir (Çizelge 6). Bu emisyon spektrumu CIE kromatik nokta ve spektral aralıkta mavi ışımaya denk gelmektedir [26].

$\mathrm{NaCa}_{4-2 x}\left(\mathrm{BO}_{3}\right)_{3}:(0.03 \mathrm{Eu}-0.03 \mathrm{Dy}, \quad 0.03 \mathrm{Nd})$ bileşiğinde göreceli ışıldama şiddetini arttırmak için Eu konsantrasyonu sabit tutularak, yardımcı aktivatör olarak kullandığımız Nd ve Dy konsantrasyonları değiştirilmiştir. Aktivatörlerin katkı oranlarına göre, bileşiklerin sönüm süreleri incelendiğinde, her bir aktivatörün, farklı katkı oranlarının ışıma ve sönüm sürelerini etkilediği ortaya konmuştur. Her bir bileşik için optimum oranlar belirlenmiştir. Sentezlenen maddeler arasında en iyi ışıma şiddetine sahip maddeler için yapılan sönüm süresi çalışmaları sonucundan, ışıma şiddetinin en yüksek değerleri için sönüm süresinin de buna bağlı olarak daha uzun olduğu görülmektedir [27]. Tuzağın enerji düzeyi ne kadar derinse, tuzaktan taşıyıcılara salınan

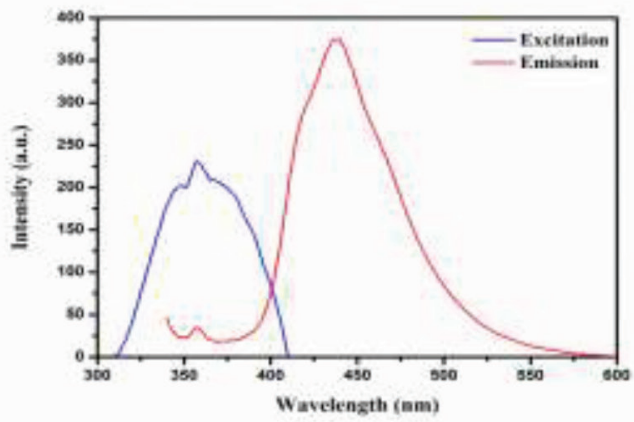

enerji de o kadar fazla olmaktadır, dolayısıyla ışıldama süresi de daha uzun gerçekleşebilmektedir.

Genellikle $3^{+}$iyon formlarının kullanıldığı lantanitler, lüminesans özelliktedir ve f-f yayınım bandları spektrumun tamamını kapsar. Bu aralık mor ötesinden (UV; GdIII), görünür (VIS; PrIII, SmIII, EullI, TbllI, DyllI, TmIIl gibi) ve yakın kızılötesi (NIR; PrIII, NdIII, HollI, ErlII, Yblll gibi) bölgeye kadar olabilmektedir [28].

Çizelge 6. En iyi ışıma şiddetine sahip $\mathrm{NaCa}_{4}\left(\mathrm{BO}_{3}\right)_{3}: x A 1: x A 2$ maddelerinin sönüm süreleri $\left(\mathrm{NaCa}_{4}\left(\mathrm{BO}_{3}\right)_{3}: x A 1: x A 2\right.$ that has the best glowing intensity: the decay curve of XA1:XA2 materials)

\begin{tabular}{ccc}
\hline $\mathbf{X}$ & Eu;Dy & Eu;Nd \\
\cline { 2 - 3 } & (ns) & (ns) \\
\hline 0,03 & 3,30 & 1,21 \\
0,05 & 2,03 & 1,45 \\
0,07 & 1,80 & 1,54 \\
\hline
\end{tabular}

Aktivatörlerin katkı oranlarına göre sönüm sürelerine bakıldığında; $\mathrm{NaCa}_{4}\left(\mathrm{BO}_{3}\right)_{3}$ : Eu; Dy maddesine ait spektrumdan da gözlendiği gibi (Şekil 8a ), (1) nolu numune için $x=0,03$ ' de sönüm süresi 3,30 ns; (2)' nolu numune için $x=0,05$ ' de sönüm süresi 2,03 ns ve $x=0,07$ konsantrasyonu için 1,80 ns olarak ölçülmüştür. En yüksek ışıma şiddetine sahip ( $x=0,03$ için) $\mathrm{NaCa}_{4}\left(\mathrm{BO}_{3}\right)_{3}: 0,03 \mathrm{Eu} ; 0,03 \mathrm{Dy}$ yapısında aynı yapının diğer katkılama konsantrasyonlarına göre ışıma şiddeti en yüksektir. Buna bağlı olarak sönüm süresi de

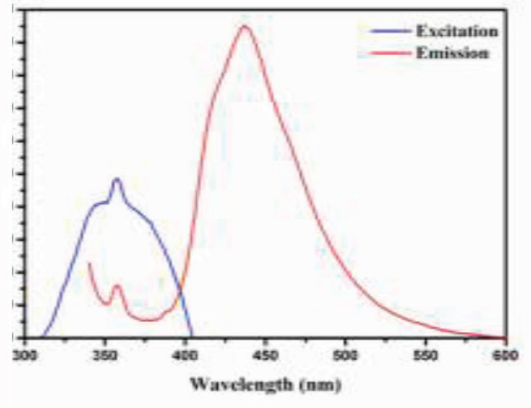

Şekil 7. a) $\mathrm{NaCa}_{4-2 x}\left(\mathrm{BO}_{3}\right)_{3}:(0.03 \mathrm{Eu}, 0.03 \mathrm{Dy})$, b) $\mathrm{NaCa}_{4-2 x}\left(\mathrm{BO}_{3}\right)_{3}:(0.07 \mathrm{Eu}, 0.07 \mathrm{Nd})$ bileşiklerinin PL spektrumları (PL spectra of compounds a) $\mathrm{NaCa}_{4-2 x}\left(\mathrm{BO}_{3}\right)_{3}:(0.03 \mathrm{Eu}, 0.03 \mathrm{Dy})$ b) $\left.\mathrm{NaCa}_{42 \mathrm{x}}\left(\mathrm{BO}_{3}\right)_{3}:(0.07 \mathrm{Eu}, 0.07 \mathrm{Nd})\right)$. 

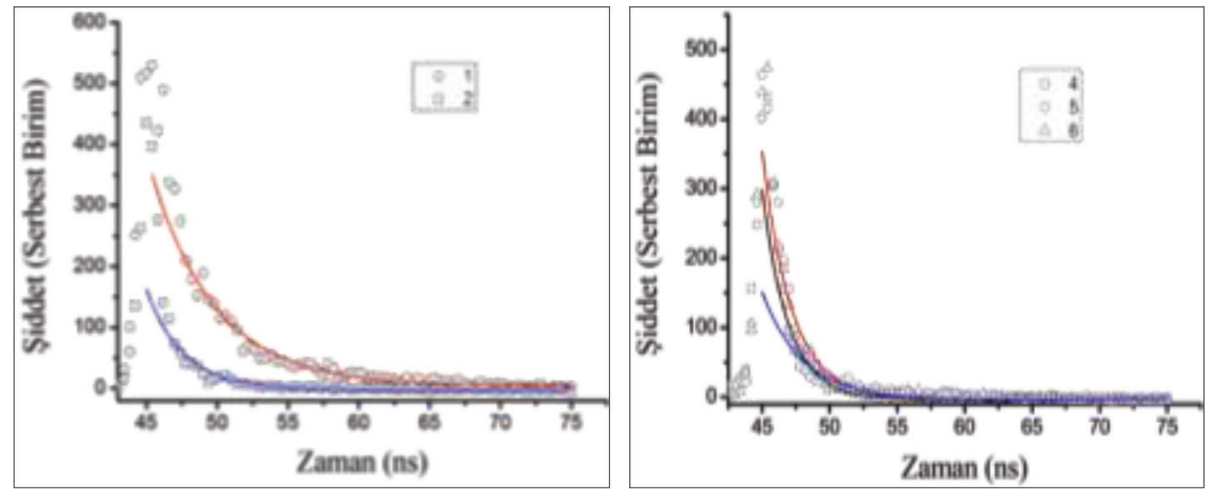

Şekil 8 (a) $\mathrm{NaCa}_{4}\left(\mathrm{BO}_{3}\right)_{3}: \mathrm{Eu}$; Dy (b) $\mathrm{NaCa}_{4}\left(\mathrm{BO}_{3}\right)_{3}: \mathrm{Eu}$; Nd Sönüm süresi Spektrumlar (Decay curve spectra of the $(\mathrm{a}) \mathrm{NaCa}_{4}\left(\mathrm{BO}_{3}\right)_{3}$ : Eu; Dy (b) $\mathrm{NaCa}_{4}\left(\mathrm{BO}_{3}\right)_{3}$ : Eu; $\mathrm{Nd}$.

en uzun olmaktadır (3,30 ns). $\mathrm{NaCa}_{4}\left(\mathrm{BO}_{3}\right)_{3}: \mathrm{Eu} ; \mathrm{Nd}$ maddesi için, Şekil 8b'de verilen (4)' nolu numune için $\mathrm{x}=0,03$ ' de sönüm süresi $1,21 \mathrm{~ns}$; (5)' nolu numune için $x=0,05$ ' de sönüm süresi 1,45 ns; (6)' nolu numune için $x=0,07$ konsantrasyonu için 1,54 ns olarak ölçülmüştür. $\mathrm{NaCa}_{4}\left(\mathrm{BO}_{3}\right)_{3}: 0,07 \mathrm{Eu} ; 0,07 \mathrm{Nd}$ maddesi en yüksek emisyon şiddeti gösteren $x=0,07$ değeri için, un uzun sönüm süresi sağlamıştır.

Lantanit katkılanarak elde edilen bileşiklerin konsantrasyon miktarının, mikro yapısı ile yüzey özelliklerine olan etkisinin, daha detaylı incelenmesi için bileşiklerin SEM ve EDX analizleri yapılmıştır. Analiz sonuçlarından en iyi emisyon şiddetine sahip örneklerin 1.00, $2.50,5.00,10.00,20.00$ ve $40.00 \mathrm{~K} X$ büyütme oranlarındaki sonuçlar vermiştir (Şekil 9). Örneğin kristal morfolojisine bakıldığında belirli bölgelerde uniform yapıda üst üste yassılaşmış şekiller gözlenmektedir [29]. Yüzey morfolojisi küçük taneli yapıda ve birbirleriyle birbirine bağlanmıştır, bu da daha büyük parçacıkların oluşmasına neden olmuştur. Ayrıca görüntüde bazı düzensiz agregasyonların oluştuğu tespit edilmiştir. Örneklerin bütün SEM mikro yapılarına bakıldığında tipik yanma reaksiyonunun doğasından kaynaklanan oluşumlar gözlenmiştir. Yanma alevinde kütle akışı ve sıcaklığın düzensiz dağılımına bağlı olarak, uniform olmayan partiküller ve yapının düzensiz şekillerde olduğu görülmüştür. Başlangıç reaksiyonunda kullanılan nitratlar ve yakıtların yanması sonucu, $\mathrm{NOx}, \mathrm{NH}_{3}, \mathrm{CO}_{2}$ gibi yanma gazlarının çıkışı, gözenekli ve boşluklu bir yapının oluşumuna yol açmıştır. Ayrıca bu durum, yü-

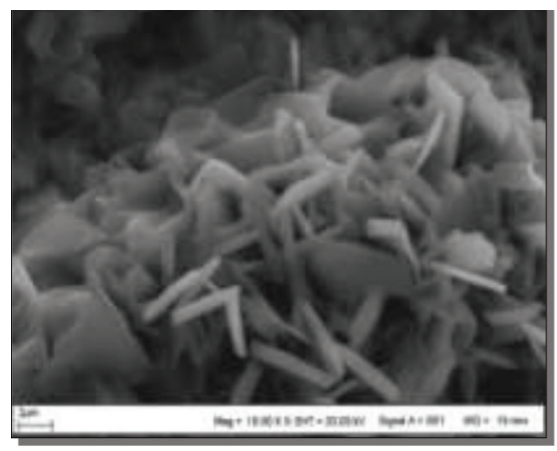

zeyde çatlaklara da neden olmuştur. Bu gözenekli toz yapısı, çok gevrek bir yapı oluşturduğundan öğütme açısından çok avantajlı bir durum sağlamıştır [30].

\section{Sonuçlar (Conclusions)}

$\mathrm{NaCa}_{4-2 x}\left(\mathrm{BO}_{3}\right)_{3}: x \mathrm{~A} 1, \mathrm{~A} 2(\mathrm{~A} 1: \mathrm{A} 2, \mathrm{Eu}: \mathrm{Dy}, \mathrm{Nd}),(\mathrm{x}=0.03$, 0.05 ve 0.07$)$ genel formülüne sahip borat bileşikler yanma yöntemi ile başarıyla sentezlenmiştir. Elde edilen örgü parametrelerinin literatürde verilen değerler ile uyum içerisinde olduğu gözlenmiştir. Sentezlenen bileşiklerin fotolüminesans, yapısal ve fiziksel özellikleri dikkatle araştırılmıştır. Lüminesans özellikli maddelerde ışımadan doğrudan lantanitlerin sorumlu olması sebebi ile elde edilen $\mathrm{NaCa}_{4}\left(\mathrm{BO}_{3}\right)_{3}$ yapısına birincil aktivatör olarak Eu kullanılmış ve bu lantanitin yanında tuzak olarak Nd ve Dy ko-aktivatörleri katkılanmıştır. Sentezlenen maddelerin UV ışığı altında 10'ar dakika süre ile ışıma yaptığı gözlenmiştir. Fakat UV ışığı kesildikten sonra ışımanın sona ermesi nedeniyle sentezlenen maddelerin, amaçlanan fosforesans özelliğe değil, floresans özelliğe sahip olduğu belirlenmiştir. Elde edilen PL spektrumlarına göre, ko-aktivatör konsantrasyonlarının arttırılmasının emisyon şiddetinin artırıcı yönün tam tersine, ışıma şiddetinde azalmaya yol açtığı görülmüştür.

\section{Teşekkürler (Acknowledgements)}

Ulusal Bor Araştırma Enstitüsü (BOREN) tarafından desteklenmiştir. Proje No: 2013.Ç0410.

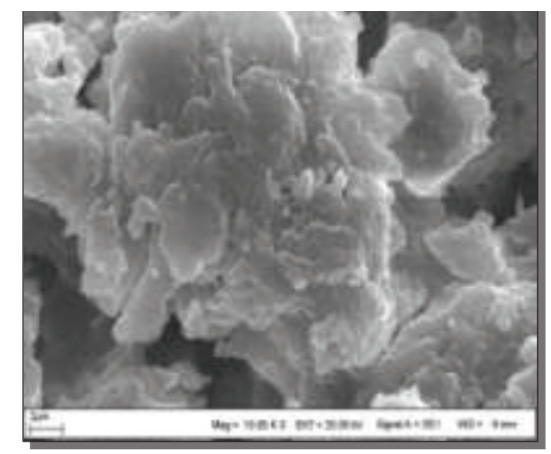

Şekil 9. $\mathrm{NaCa}_{4-2 x}\left(\mathrm{BO}_{3}\right)_{3} ; \mathrm{xEu}, \mathrm{xDy}-\mathrm{Nd}$ bileşiklerine ait SEM fotoğrafları (SEM micrographs of $\mathrm{NaCa}_{4-2 x}\left(\mathrm{BO}_{3}\right)_{3} ; \mathrm{xEu} \mathrm{xDy}-\mathrm{Nd}$ compounds). 


\section{Kaynaklar (References)}

[1] Becker P., Borate materials in nonlinear optics, Adv. Mater., 10, 979-992, 1998.

[2] Chen C., Lin Z., Wang Z., The development of new borate-based UV nonlinear optical crystals, Appl. Phys. B, 80, 1-25, 2005.

[3] Aka G., Brenier A., Self-frequency conversion in nonlinear laser crystals, Optic Mater., 22, 89-94, 2003.

[4] Wu L., Chen X., Dai Li L., Xu Y., Zhao M., Synthesis and ab initio X-ray powder diffraction structure of the new alkali and alkali earth metal borate $\mathrm{NaCa}\left(\mathrm{BO}_{3}\right)$, Acta Cryst., C61 i32, 2005.

[5] Sun J., Lian Z., Shena G., Shen D., Blue-white-orange color-tunable luminescence of $\mathrm{Ce}^{3+} / \mathrm{Mn}^{2+}$ co-doped $\mathrm{NaCaBO}_{3}$ via energy transfer: potential single-phase white-light-emitting phosphors, RSC Adv., 3, 18395, 2013.

[6] Chen C., Wu Y., Li R., Growth of large Mo O single 18 52 crystals by a vapor phase method, J. Crys. Growth, 99, 708-715, 1990.

[7] Fan T. Y., Huang C. E., Hu B. Q., Eckhardt R. C., Fan Y. X., Bayer R. L., Feigelson R. S., Second harmonic generation and accurate index of refraction measurements in ux-grown $\mathrm{KTiOPO}_{4}$, Appl. Optics, 26, 2391-2394, 1987.

[8] Harrison W. T. A., Gier T. E., Stucky G. D., The synthesis and $\mathrm{Ab}$ initio structure determination of $\mathrm{Zn} 4 \mathrm{O}\left(\mathrm{BO}_{3}\right)_{2}$, a microporous, zinc borate constructed of "sused" subunits, of three- and ve-membered rings, Ange. Chem. Inter. Ed., 32, 724-761, 1993.

[9] Yukihara E. G., Milliken E. D., Dull B. A., Thermally stimulated and recombination processes in $\mathrm{MgB}_{4} \mathrm{O}_{7}$ investigated by systematic lanthanide doping, J. Luminescence, 154, 251-259, 2014.

[10] Shyichuk A., Lis S., Meinrath G., Structure modeling of terbium doped strantium-lanthanım borate, J. Rare Earths, 32,3, 248, 2014.

[11] Guo C., Ding X., Seo H., Ren., Z, Bai J., Luminescent properties of UV excitable blue emitting phosphors $\mathrm{MSr} 4(\mathrm{BO} 3) 3: \mathrm{Ce} 3+(\mathrm{M}=\mathrm{Li}$ and $\mathrm{Na})$, J. Alloys Compd., 509, 4871, 2011.

[12] Zhang, X. Zhang, J. Dong, Z. Shi, J. Gong M., Concentration quenching of $\mathrm{Eu}^{2+}$ in a thermal-stable yellow phosphor $\mathrm{Ca}_{2} \mathrm{BO}_{3} \mathrm{Cl}$ : $\mathrm{Eu}^{2+}$ for LED application, J. Luminescence 132, 914, 2012.

[13] Ju G., Hu Y., Wu, H., Fu C., Mu Z., Kang F., A red-emitting heavy doped phosphor $\mathrm{Li}_{6} \mathrm{Y}\left(\mathrm{BO}_{3}\right)_{3}: \mathrm{Eu}^{3+}$ for white light-emitting diodes, Opt. Mater., 33, 1297, 2011.

[14] Diaz, A., Keszler, D. A., Eu24 Luminescence in the bo- rates $\mathrm{X}_{2} \mathrm{Z}\left(\mathrm{BO}_{3}\right)_{2}(\mathrm{X}=\mathrm{Ba}, \mathrm{Sr} ; \mathrm{Z}=\mathrm{Mg}, \mathrm{Ca})$ Chem. Mater., 9 (10), 2071-2077, 1997.

[15] Zhang X., Seo H. J., Luminescence properties of novel $\mathrm{NaBa}_{4}\left(\mathrm{BO}_{3}\right)_{3}: \mathrm{Ce}^{3+}, \mathrm{Eu}^{3+}$ Phosphors, Physica $\mathrm{B}, 406$, 77-79, 2011.

[16] Yashashchandra D., Shyam Bahadur R., J. Am. Ceram. Soc. 93, 56, 2010.

[17] Wu. L, Chen X. L., Xu Y. P., Sun Y. P., Structure determination and relative properties of novel noncentrosymmetric borates $\mathrm{MM}_{4}^{\prime}\left(\mathrm{BO}_{3}\right)_{3}\left(\mathrm{M}=\mathrm{Na}, \mathrm{M}^{\prime}=\mathrm{Ca}\right.$ and $\mathrm{M}=\mathrm{K}, \mathrm{M}^{\prime}=\mathrm{Ca}$, Sr)" Inorg. Chem., 45, 7., 2006.

[18] Pekgozlu I., Erdogmus E., Cubuk E., Basak A.S. Synthesis and photoluminescence of $\mathrm{LiCaBO}_{3}: \mathrm{M}$

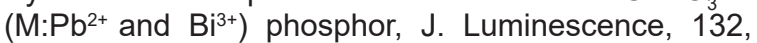
1394-1399, 2012.

[19] Rulmont A., Almou A., Spectrochim. Acta 45A (5) 603, 1989.

[20] Bhagat S. P., Gawande A. B., Omanwar S. K., Photoluminescence study of a novel UV emitting phosphor $\mathrm{Sr}_{2} \mathrm{Mg}\left(\mathrm{BO}_{3}\right)_{2}: \mathrm{Pb}^{2+}, \mathrm{Gd}^{3+}$, Optic. Mater., 40, 36-40, 2015.

[21] Martın O. O., Joseph O. O., Dejene F. B., Solutioncombustion synthesis and photoluminescence properties of $\mathrm{YBO}: \mathrm{Tb}^{3+}$ phosphor powders, P. B: Cond. Matter., Vol. 439, 133-136, 2014.

[22] Bajaj N. S., Omanwar S. K., Combustion synthesis and luminescence characteristics of $\mathrm{NaSr}_{4}\left(\mathrm{BO}_{3}\right)_{3}: \mathrm{Tb}^{3+}, \mathrm{J}$. Luminescence 148, 169-173, 2014.

[23] Blasse G., Wanmaker W. L., Tervrugt J. W., Bril A., Philip. Res. Repts., 23,189, 1968.

[24] Yamzaki K., Nakabayashi H., Kotera Y., Ueno A. J., Electrochem. Soc., 133, 657, 1986.

[25] Matsuzawa,T., Takeuchi N., Aoki Y., Murayama Y., Electrochem., 143. 8., 1996.

[26] Ingle J. T., Sonekar R. P., Omavwar S. K., Wang Y., Zhao $Y$., Combustion synthesis and photoluminescence study of novel red phosphor $\left(\mathrm{Y}_{1-\mathrm{x}-\mathrm{y}}, \mathrm{Gd}_{\mathrm{x}}\right) \mathrm{BaB}_{9} \mathrm{O}_{16}$ for display and lighting, J. Alloys Comp., 608, 235-240, 2014.

[27] Gawande A. B., Sonekar R. P., Omavwar S. K., J. Luminescence, 149, 200-203, 2014.

[28] Jiang L., Chang C., Mao D., Feng C., Luminescent properties of $\mathrm{Ca}_{2} \mathrm{MgSi}_{2} \mathrm{O}_{7}$ phosphor activated by $\mathrm{Eu}^{2+}$, $\mathrm{Dy}^{3+}$ and $\mathrm{Nd}^{3+}$, Opt. Mat., 27, 51-55, 2004.

[29] Qiao X., Cheng Y., Qin L., Qin C., Cai P., Kim Sun I., Seo H. J., Coprecipitation synthesis, structure and photoluminescence properties of $\mathrm{Eu}^{3+}$ doped sodium barium borate, J.Alloys Comp., 617, 946-951, 2014.

[30] Luitel H. M., Watari T., TorikaiT., Yada M., Luminescent properties of $\mathrm{Cr}^{3+}$ doped $\mathrm{Sr}_{4} \mathrm{Al}_{14} \mathrm{O}_{25}$ : Eu/Dy blue-gren and red phosphor, Opt. Mat., 31,1200-1204, 2009. 